\title{
O ESPELHO DE MACHADO DE ASSIS REFLETINDO UM NACIONALISMO BRASILEIRO "AUTÊNTICO"
}

Bruna Estevão

Eduardo da Cruz Franciane Mochenski

RESUMO: O nacionalismo é um conceito presente na discussão literária brasileira, além de ser recorrentemente estudado por grandes nomes da historiografia. Machado de Assis, durante toda a sua vida dedicou-se a escrever obras que o consagrariam como um dos maiores escritores brasileiros. Com isso, o presente artigo analisa e discute o conceito de nacionalismo brasileiro dentro da obra Papéis Avulsos de Machado de Assis, utilizando como fonte, especificamente o conto $O$ espelho que possui símbolos característicos que fazem alusão ao ideal nacionalista do autor.

PALAVRAS-CHAVE: nacionalismo; nacionalismo brasileiro; Machado de Assis; Papéis Avulsos; O espelho.

\section{Nacionalismo - um conceito que perpassa a literatura}

Certos conceitos são dotados de discussões que não encerram nesse ou naquele autor, mas permanecem ao longo de anos e sem um fim definido. Esse é o caso dos conceitos de pátria e nação, termos que fazem parte do mundo ocidental desde o século XVIII pelo menos e emergiram na luta política e social dos povos europeus no Novo Mundo.

Hélio Jaguaribe expõe que o conceito de nação, em termos objetivos, está relacionado à existência de um povo, dotado de vínculos comuns, como a raça e a tradição cultural, habitando certo território e integrado por um sistema comum de governo. Dessa forma, o termo nação resume-se na vontade prévia de certo povo de constituí-la e mantê-la. Seria, portanto, o propósito nacional que 
constituiria a nação. O conceito de nacionalismo surge dessa forma devido aos problemas enfrentados por cada nação ao procurar realizar um destino comum, que proporcionasse à sua população o sentimento de pertencimento a determinado grupo ou sociedade.

Os trabalhos que discutem as ideologias formadoras da nação dividem-se em dois enfoques principais, como afirma Lucia Lippi Oliveira: de um lado o grupo que evidencia os aspectos culturais da nação em contraposição à idéia de progresso, e do outro o grupo que ressalta valores políticos desvalorizando os elementos culturais. Oliveira afirma que essa distinção entre nacionalismo cultural e político foi proposta por inúmeros autores, entre eles Kohn (1973) e ela nos ajuda a interpretar correntes e autores dedicados ao estudo da construção ideológica brasileira. Entretanto, a autora afirma que essa distinção não é rígida e que ela corresponde a uma construção analítica.

Barbosa Lima Sobrinho afirma que o termo nacionalismo não é dotado de uma única definição que englobe todas as características particulares de cada grupo nacionalista. Sobrinho defende que o nacionalismo pode ser uma atitude de extrema direita, como o fascismo e o nazismo, ou de esquerda, entretanto, entre esses dois extremos podem ocorrer inúmeras outras definições variadas não só no tempo dos acontecimentos, mas no espaço, de país a país, adaptando-se a circunstancias e problemas diferentes em cada nação.

Por sua vez, Kohn aponta que o nacionalismo pode ser considerado uma força capaz de impulsionar a organização de um povo, sendo que a o ideal de nação passa a ser colocado em local de destaque, integrando diferentes tradições, religiões, etnias e classes.

O conceito de nacionalismo teve uma história complexa e diferenciada em cada contexto nacional. Eric Hobsbawn aponta que o termo nacionalismo surgiu na França, nos fins do século XIX

Para descrever grupos ideológicos de direita na França e na Itália, que brandiam entusiasticamente a bandeira nacional contra os estrangeiros, os liberais, os socialistas, e a favor daquela expansão agressiva de seus 
próprios Estados, que viria a ser tão característica de tais movimentos. (HOBSBAWN, 1988, p. 204)

Nesse momento, termos como povo e nação ganham valor na França, sendo o povo identificado como o "terceiro Estado" e fazendo parte integrante da nação francesa. Rousseau expressou em seus escritos que a soberania nacional não estava no rei, mas no povo e que o homem comum era o que formava a nação.

Iluministas do século XVIII como Montesquieu e Voltaire identificaram a nação como uma comunidade distinguida por traços intelectuais e morais próprios. Essas idéias abriram espaço para novas discussões a respeito do ideal de nação. Na Alemanha, por exemplo, os ideais da cultura nacional juntaram-se a experiência histórica do Estado prussiano, como afirma Lúcia Lippi Oliveira. Meinecke considera que

na França os setores médicos e os homens de letras criaram juntos uma nova idéia de nação, enquanto que na Alemanha o espírito nacional emergiu como um subproduto do esforço intelectual de grandes poetas e pensadores (OLIVEIRA, 1990, p. 31).

Os primeiros pensadores que elaboraram as idéias de um nacionalismo cultural alemão estão diretamente ligados ao Iluminismo, como o caso de Herder, Goethe e Kant. Esse nacionalismo cultural alemão, segundo Oliveira, tendeu a rejeitar a liberdade individual como principio fundador da nação e o espírito nacional assumiu um sentido místico e passou a ser visto como fonte de valores e conduta.

Hobsbawm afirma que a palavra "nacionalismo” passou a ser usada igualmente para todos os movimentos que consideravam a causa nacional como de grande importância política, aqueles que defendiam o direito de formar um Estado independente, destinado a um grupo nacionalmente definido. $\mathrm{O}$ autor afirma que a base dos nacionalismos de todos os tipos era igual, ou seja, a identificação emocional com sua nação. 
Retomando Barbosa Lima Sobrinho, o autor afirma que uma característica do nacionalismo é a presença de um antagonismo, de uma diversificação de interesses entre grupos humanos, vinculados a territórios diferentes.

O antagonismo que se faz sentir, por exemplo, entre uma metrópole e a colônia, que veio a emancipar-se e a se tornar Nação, poderá classificar-se como nacionalismo, se traduzindo numa aspiração ou num programa de ação. Mas se esse antagonismo surge entre regiões ou territórios de uma determinada nação, mesmo quando traduza diferenciações de classes ou de atividades econômicas, não chega a constituir um nacionalismo. Seria apenas regionalismo. Mas, se passa a influir na luta pela emancipação política dessa região, há de figurar entre os movimentos pioneiros do nacionalismo desse grupo humano, mesmo ainda sem a presença da Nação, mas como um esforço para criá-la, para lhe dar forma e substancia (SOBRINHO, 1995, p. 09).

Partimos então para a análise do nacionalismo brasileiro e suas primeiras manifestações.

Lúcia Lippi Oliveira utiliza das palavras de Afonso Arinos de Melo Franco para afirmar a idéia de que "foi a partir do terceiro século da colonização que o Brasil transformou-se claramente em uma nação" (FRANCO, 1975, p. 73). A definição gradativa do território, a formação de uma mentalidade luso-brasileira e o sentimento de independência política que surge com a decadência da mineração caracterizam um sentido mais acentuado de nacionalidade do que o próprio processo de independência brasileiro, que pouco contribuiu com a construção de um sentimento nacional.

Na história literária também surgem discussões acerca do momento inicial do espírito nacionalista brasileiro e para tanto, Oliveira utiliza-se de dois autores brasileiros que trabalham com 0 tema: Antônio Cândido e Afrânio Coutinho.

Antônio Cândido, ao estudar o espírito nacional em sua vertente literária afirma que

é com os chamados árcades mineiros, as últimas academias e certos intelectuais ilustrados, que surgem homens de letras formando conjuntos 
orgânicos e manifestando em graus variáveis a vontade de fazer literatura brasileira (CÂNDIDO, 1969, p. 25).

Esse desejo de fazer uma literatura brasileira esboça a vontade de fazer uma literatura independente da metrópole, expondo temas e sentimentos da nação brasileira.

Afrânio Coutinho, por sua vez, recua a origem de uma literatura brasileira para o início da ocupação portuguesa, afirmando que foi nesse momento que se criou um homem novo em terras brasileiras, esse homem, tinha mentalidades, interesses e sentimentos diferentes dos portugueses da metrópole e diferentes dos habitantes naturais do território. Dessa forma, dar-se-ia a criação de uma literatura genuinamente brasileira, com características próprias. Contudo, Coutinho afirma que a libertação total de idéias portuguesas veio com a proclamação da República:

A República, com sua 'capacidade de criar Brasil, dentro do Brasil', como assinalou Gilberto Amado, clareou a nossa consciência de ser brasileiros, fez-nos captar a resposta autodefinidora, depois de um século de perguntas e pesquisas sobre o que era ser brasileiro, e quais as características da nacionalidade e da literatura nacional (COUTINHO, 1976, p. 11).

Para Afrânio Coutinho, há três vertentes do pensamento sobre o nacionalismo na literatura. A primeira considera a literatura como o instrumento de um ideal nacional, a serviço da exaltação das características de um povo sobre as dos demais. A segunda vertente enfatiza o pitoresco, presente no regionalismo, no qual identifica o verdadeiro caráter nacional. Por fim, a terceira, que recebe a adesão do autor, constituiria o “autêntico" nacionalismo. O exemplo ideal é dado por Machado de Assis no texto Instinto de nacionalidade:

Não há dúvida de que uma literatura, sobretudo uma literatura nascente, deve principalmente alimentar-se dos assuntos que lhe oferece a sua região; mas não estabeleçamos doutrinas tão absolutas que a empobreçam. O que se deve exigir do escritor, antes de tudo, é certo sentimento íntimo, que o torne homem do seu tempo e do seu país, ainda quando trate de assuntos remotos no tempo e no espaço. 
Machado de Assis recorre a Willian Shakespeare para tornar sua idéia mais clara e compreensível:

E perguntei mais, se o Hamlet, o Otelo, o Júlio César, a Julieta e Romeu têm alguma coisa com a história inglesa nem com o território britânico, e se, entretanto, Shakespeare não é, além de um gênio universal, um poeta essencialmente inglês (ASSIS, 1973, p. 804).

A questão da nação brasileira como uma unidade própria emergiu em diferentes momentos do processo de autoconsciência dos intelectuais brasileiros, e um deles, segundo Lúcia Lippi Oliveira, ocorreu na segunda metade do século XIX, com a chamada "geração de 1870”. José Veríssimo foi um dos críticos literários que melhor compreendeu o significado das transformações que estão ocorrendo nesse momento e denomina-as de "modernismo". Veríssimo afirma que:

O movimento de idéias que antes de acabada a primeira metade do século XIX se começara a operar na Europa com o positivismo comtista, o transformismo darwinista e o evolucionismo spenceriano, o intelectualismo de Taine e Renan e quejandas correntes de pensamento, que, influindo na literatura, deviam pôr um termo ao domínio exclusivo do romantismo, só se entrou a sentir no Brasil, pelo menos, vinte anos depois de verificada a sua influência ali. Sucessos de ordem política e social, e ainda de ordem geral, determinaram-lhe ou facilitaram-lhe a manifestação aqui. Foram, entre outros, ou os principais: a Guerra do Paraguai, acordando o sentimento nacional meio adormecido desde o fim das agitações revolucionárias conseqüentes à Independência (...). Também a Revolução Espanhola de 1868 e conseqüente advento da República em Espanha (...). Esta propaganda republicana teve um pronunciado caráter intelectual e interessou grandemente os intelectuais, pode-se dizer que toda a sua parte moça, ao menos (VERÍSSIMO, 1969, pp. 28-29).

O pensamento dos autores que produziram seus trabalhos entre 1870 e 1914 foi dominado pelo sentido de atualização, de modernização. Seu projeto era superar o atraso cultural ao qual estava submetido o Brasil, a fim de que pudesse alcançar a parcela mais 
avançada da humanidade. É, então, nesse período que se encaixa Machado de Assis com sua obra "Papéis Avulsos".

\section{O espelho - farda, pertencimento e nacionalismo}

No esboço apresentado acima, procuramos discorrer sobre o conceito de nacionalismo, utilizando referenciais teóricos conceituados no assunto. Nesse contexto, nosso propósito volta-se a analisar o nacionalismo dentro da obra de Machado de Assis, mais especificamente no conto $O$ espelho, publicado no livro Papéis Avulsos, em 1882. Nossa problemática parte do pressuposto de que esse conto é uma alegoria ao sentimento de nacionalismo, entendido por nós como o sentimento de pertencimento a uma nação. Compartilhamos da idéia de Sidney Chalhoub de que

sem dúvida, é um desafio interrogar esses documentos [contos de Machado de Assis],descobrir as intenções de comentário e de crítica social e política que eles carregam (CHALHOUB, 2005, p. 67).

Porém, acreditamos que a clara alusão ao sentimento de nacionalismo presente no conto nos guiará a compreender a intenção de Machado de Assis.

Além de compreender o conto, analisamos como Machado de Assis, enquanto um autor em sua fase realista, transporta para o papel a realidade da sociedade em que vive.

\section{***}

Papéis Avulsos (1882) é o terceiro livro publicado por Machado de Assis em sua fase realista. É uma obra composta por narrativas curtas denotando um momento de ruptura na escrita do autor, a começar pelo título, que faz uma alusão a casualidade. É o próprio Machado que faz a advertência no início do livro:

Este título de Papéis avulsos parece negar ao livro uma certa unidade; faz crer que o autor coligiu vários escritos de ordem diversa para o fim de os 
não perder. A verdade é essa, sem ser bem essa. Avulsos são eles, mas não vieram para aqui como passageiros, que acertam de entrar na mesma hospedaria. São pessoas de uma só família, que a obrigação do pai fez sentar à mesma mesa (ASSIS, 1882).

O espelho, sub-titulado "esboço de uma nova teoria da alma humana”, relata a história de uma conversa, entre quatro cavalheiros, na qual um deles, Jacobina, inicia sua teoria de que o ser humano seria possuidor de duas almas - uma exterior e outra interior. Segundo o personagem, a alma exterior pode mudar constantemente e, de modo a fazer-se entender a seus colegas, conta-lhes um fato ocorrido a ele próprio: diz ele que, aos seus vinte e cinco anos, fora nomeado alferes da Guarda Nacional, episódio este que rendeu o orgulho a família, além de muita bajulação. Prossegue dizendo que então, certa vez, foi visitar uma tia no sítio e lá ficou por mais de um mês. Diz ele que os elogios eram incessantes e que lá pelas tantas, acostumou-se mais a ser o "sr. Alferes" que o "homem Jacobina". Ganhou até um espelho, para admirar-se, provindo das fidalgas vindas em 1808, com a família real. Entretanto, é quando sua tia vai viajar para visitar uma filha enferma, que se desenrola o drama. Sem a bajulação diária (até mesmo dos escravos que fogem após a viagem da tia), o personagem encontra-se e sente-se solitário e vazio. Somente quando se olha no espelho, fardado ${ }^{1}$, é que se sente vivo outra vez.

Especificamente nesse conto, compreendemos que há referência a identidade nacional pessoal. Isso é bastante claro no sentimento produzido no personagem pelo uso da farda que representaria a nacionalidade. Enquanto Jacobina sente solitário e vazio, vemos um ser solitário e vazio. Porém, ao olhar-se no espelho e ver-se fardado, sente-se outra vez não mais sozinho, mas parte de algo, de uma nação, ressaltando o sentimento de pertencimento explorado por Hélio Jaguaribe. Trabalhamos nesse momento com um

${ }^{1}$ Pois, num primeiro momento quando se posta diante do espelho sem a farda, não vê "uma figura nítida e inteira, mas vaga, esfumada, difusa, sombra de sombra" (ASSIS, 1882). 
símbolo. A farda simbolizando ou representando a nacionalidade do personagem e exaltando o seu sentimento, o seu pertencimento, a sua nacionalidade.

Nas referências históricas do conto, o autor John Gledson, utilizando das palavras do próprio Machado de Assis, afirma que a própria descrição do espelho já forneceria o principal referencial:

Era um espelho que lhe dera a madrinha, e que esta herdara da mãe, que o comprara a uma das fidalgas vindas de 1808 com a corte de d. João VI. Não sei o que havia nisso de verdade, era a tradição. O espelho estava naturalmente muito velho; mas via-se lhe ainda o ouro, comido em parte pelo tempo, uns enfeites de madrepérola e outros caprichos do artista. Tudo velho, mas bom (...) (GLEDSON, 2006, p. 74).

Apoiado nesse referencial, Gledson faz também outra analogia com o conto. Segundo ele, 1808 seria o momento em que a nação brasileira teria se visto no "espelho", tornando-se consciente de si própria. O autor alude para que em 1808 a identidade nacional era tão "imperceptível quanto a imagem de Jacobina no espelho" (GLEDSON, 2006, p.76), quando olhou da primeira vez. Gledson também relaciona a descrição do espelho com a própria descrição da imagem da cultura portuguesa do século XVIII, da qual os brasileiros teriam herdado tal cultura, pela qual viam a si mesmos: "apodrecida, oca e puramente ornamental” (GLEDSON, 2006, p.76).

Retomando a análise do conto, encontramos na passagem onde o personagem discorre sobre as duas almas do ser humano estabelecendo referências com o nacionalismo brasileiro, desperto já nesse momento:

A alma exterior pode ser um espírito, um fluído, um homem, muitos homens, um objeto, uma operação. Há casos, por exemplo, em que um simples botão de camisa é uma alma exterior de uma pessoa (...) Está claro que o ofício dessa segunda alma é transmitir a vida, como a primeira; as duas completam o homem, que é, metafisicamente falando, uma laranja. Quem perde uma das metades, perde naturalmente metade da existência (ASSIS, 1882). 
Associamos a alma exterior de Jacobina à farda, que no nosso caso, representa a nação. Entendemos então, a partir da explicação sobre a segunda alma do ser humano, que quando Jacobina se vê sem a farda no espelho, está claro que o personagem não está completo. Falta-lhe o sentimento de pertencimento a algo, por isso, sente-se vazio e solitário.

John Gledson defende que o conto apresenta uma "crise de identidade":

Não foi então por acaso que Machado recorreu ao conto, tão adequado à dramatização de crises de identidade, para uma primeira solução do problema, isto é, a sua primeira tentativa de encarnar a nação num único personagem. "O espelho" é seguramente o texto crucial nesse contexto porque, aqui pela primeira vez, a fim de dar rosto às dúvidas sobre a identidade da nação, esta é encarnada por um personagem cuja identidade é, ela própria, posta em dúvida (GLEDSON, 2006, p. 89).

Nesse contexto, somos tentados a discordar da interpretação que o autor faz do conto, quando entende que a identidade do personagem é posta em dúvida. Acreditamos que a análise deva ser feita pelo viés do "descobrimento" da identidade e não da dúvida dela, tendo em vista que a dúvida acarreta a incerteza do fato e não o "não-saber" dele, que seria o caso do conto. Pois Jacobina descobre, ao olhar no espelho, que se sente bem, valorizado, pertencendo a um grupo importante para sua vida com a farda e não coloca em dúvida esse fato, questionando se a farda faria ou não sentir-se melhor.

Em relação ao período no qual Machado de Assis escreveu o conto, temos que a literatura brasileira estava em sua etapa realista. Após a etapa intitulada "romantismo", na qual se procurou enaltecer símbolos nacionais e, a partir da qual, acreditamos na intenção que havia em criar-se um sentimento de pertencimento à nação brasileira, negando os valores da antiga metrópole, houve, no Brasil, a fase realista da literatura, na qual se deixou de lado a escrita para o ócio dos leitores e buscou-se escrever a verdade. Nesse contexto, encontramos na autora Mônica Pimenta Velloso um arsenal para discutir nossa proposta de como Machado de Assis, em sua fase 
realista, discute o nacionalismo numa forma alegórica, como a apresentada no conto.

A literatura realista seria, como já mencionamos, o relato de problemas reais, através de uma escrita "real". A autora menciona que "se o homem é fruto do meio, sua obra deve, conseqüentemente, refletir esse meio" (VELLOSO, 1988). É nesse contexto então que a autora intitula Machado de Assis como "literatura rebelde”, pois

Um ponto é claro: Machado não recorre ao gênero documental, escapando assim à famosa simetria autor-obra. Por isso é acusado de uma dupla alienação: em relação à nação, quando não se interessa pelos problemas públicos, e em relação a si próprio, quando nega suas origens. Logo, sua obra não se assemelha a ele que é pobre e mestiço - nem à sua pátria, porque ele se identifica mais com os ideais gregos e ingleses. A simetria se realizaria se Machado se visse tal como é, ou seja, se escrevesse um "romance mulato", com experiência de suas origens e pua psique (VELLOSO, 1988).

A autora entende que "recusando o ideal da observação científica e a tradição descritiva, típicos da narrativa naturalista, o autor [Machado] gera controvérsias (VELLOSO, 1988). Entretanto, antes que possamos discordar da autora, ela fornece o ponto-chave para que entendamos o porquê dessa controvérsia: a subjetividade. Machado de Assis usou-se da fiç̧ão em seus contos e da subjetividade para transportar os problemas sociais brasileiros de sua época, para o papel, fato esse que suscitou a seus contemporâneos o entendimento de que Machado não daria importância ao seu contexto social. Nas palavras de Velloso

Em suma: cobra-se a ausência, faltam paisagens, pessoas; falta a descrição! É a "estética do visível” que quer a representação fiel do real, a fotografia exata, o milímetro dos detalhes. Machado recusa esta receita literária. Ao invés do retrato bem comportado, prefere falar pelas pulsões e contradições dos seus personagens, deixando que o social aí apareça (VELLOSO, 1988). 
Com isso, podemos concluir que o nacionalismo estava presente na obra de Machado de Assis, muitas vezes de maneira subjetiva, ou em forma de crítica a sociedade. Entretanto a importância do sentimento de pertencimento à nação aparece firmemente na fonte aqui trabalhada, evidenciando o fato já citado e trabalhado pelo próprio autor aqui analisado de que uma literatura deve alimentar-se dos assuntos da sua região, criando-se autores do seu tempo e do seu país, evidenciando fortes traços nacionalistas e fazendo uma literatura que defende o nacionalismo "autêntico", apresentado por Afrânio Coutinho e defendido por Machado de Assis.

\section{BIBLIOGRAFIA}

ASSIS, Machado. Obra completa. Rio de Janeiro, Aguilar, 1973. . Papéis avulsos. Belo Horizonte: Itatiaia. 2006.

CÂNDIDO, Antônio. Formação da literatura brasileira (momentos decisivos). $3^{\mathrm{a} e d . ~ S a ̃ o ~ P a u l o, ~ M a r t i n s, ~} 1969,2^{\circ}$ v..

CHALHOUB, Sidney. História em cousas miúdas. São Paulo, 2005. COUTINHO, Afrânio. Conceito de literatura brasileira. Rio de Janeiro/Brasília, Pallas/INL, 1976.

FRANCO, Afonso Arinos de Melo. Problemas políticos brasileiros. Rio de Janeiro, José Olympio, 1975.

GLEDSON, John. Por um novo Machado de Assis: ensaios. São Paulo: Companhia das Letras, 2006.

HOBSBAWN, Eric J. A Era dos Impérios 1875-1914. Rio de Janeiro, Paz e Terra, 1988.

JAGUARIBE, Hélio. Nacionalismo na atualidade brasileira. Rio de Janeiro: ISEB/MEC, 1958.

KOHN, Hans. Nationalism. In: WIENER, Philip (ed.). Dictionary of the history of ideas. New York, Charles Scribner's Sons, 1973 
OLIVEIRA, Lucia Lippi. A questão nacional na Primeira República. São Paulo: Brasiliense, 1990.

SOBRINHO, Barbosa Lima. Desde quando somos nacionalistas? Rio de Janeiro: editora Vozes, 1963

VELLOSO, Mônica Pimenta. A Literatura como espelho da nação: A crítica literária no Estado Novo. Revista de Estudos Históricos, Rio de Janeiro, 1988.

VERÍSSIMO, José. O modernismo. In: História da literatura brasileira. 5aed. , Rio de Janeiro, José Olympio, 1969. 